\title{
Dinámicas de diferenciación y desigualdades. El caso de las intervenciones sociales hacia mujeres inmigradas en España ${ }^{\star}$
}

\author{
Caterine Galaz Valderrama ${ }^{\star *}$
}

\section{RESUMEN}

Los dispositivos de intervención social por los que atraviesan las mujeres inmigradas producen efectos de dominación mediante el uso de estrategias de diferenciación social. A partir del estudio de las prácticas y discursos presentes en los servicios de atención a mujeres inmigradas en España, se observan algunos procesos de subjetivación de profesionales y usuarias a partir de mecanismos de diferenciación en términos de género, origen nacional y clase. Estos procesos, basados en una diferenciación jerarquizada, tienen como uno de sus efectos la constitución de la categoría "mujer del tercer mundo" (Mohanty, 2003), entendida como una otra totalmente diferente a partir de un exceso culturalista. Esto lleva a que la intervención busque encauzarlas en una correcta inserción social en la sociedad de instalación, eludiendo las experiencias particulares y, en muchos casos, omitiendo las desigualdades sociales del contexto de instalación que afectan sus vidas.

Palabras clave: mujeres inmigrantes, inmigración, inclusión/exclusión social, gubernamentalidad

\section{Dinâmica de diferenciação e desigualdades. $O$ caso de intervenções sociais para as mulheres imigrantes em Espanha}

\section{RESUMO}

Os dispositivos de intervenção social que atravessam as mulheres imigrantes produzem efeitos de dominação por meio de estratégias de diferenciação social. A partir do estudo das práticas e discursos presentes nos serviços de atenção para as mulheres imigrantes em Espanha, se observam alguns processos de subjetivação de profissionais e usuários a partir de mecanismos de diferenciação em termos de género, origem nacional e de classes. Estes

Artículo recibido: 02/07/2015. Artículo aprobado el 1/10/2015.

* Chilena/Española. Académica Trabajo Social, Universidad de Chile. E mail: cgalazvalderrama@u.uchile.cl 
processos, com base numa diferenciação hierárquica, têm como um dos seus efeitos a formação da categoria "Mulher do Terceiro Mundo" (Mohanty, 2003), entendida como uma totalmente diferente a partir de um excesso culturalista. Isto conduz à que a intervenção procure levá-las numa correta integração social na sociedade de instalação, evitando as experiências particulares e, em muitos casos, omitindo as desigualdades sociais do contexto de instalação que afetam suas vidas.

Palavras-chave: mulheres imigrantes, imigração e exclusão / inclusão social, governamentalidade

\title{
Dynamics of differentiation and inequality. The case of social interventions to immigrant women in Spain
}

\author{
ABSTRACT
}

The mechanisms of social intervention experienced by immigrant women produce effects of domination by using strategies of social differentiation. From the study of practices and discourses present in services for immigrant women in Spain, some processes of subjectivity of professionals and users are observed in mechanisms of differentiation in terms of gender, national origin and class. One of the effects of these processes, based on a hierarchical differentiation, is the formation of the category "Third World Woman" (Mohanty, 2003), understood as an "other" totally different from a culturalist excess. This leads to interventions seeking the control of their proper social integration into this new society, bypassing the particular experiences and, in many cases, omitting the social inequalities of the context affecting their lives.

Keywords: immigrant women, immigration, social inclusion/social exclusion, governmentality

\section{El tránsito de las mujeres inmigradas por una matriz de poder}

Las maneras en las que las personas inmigradas en la sociedad global se instalan en los territorios que actualmente se configuran como receptores de flujos migratorios en Europa, están condicionadas por una matriz de poder semiótico-material en la que están presentes una diversidad de elementos tales como las leyes de extranjería, las leyes internas de instalación de los flujos migratorios, los diversos procesos de inclusión/exclusión social que se evidencian, discriminación y prejuicios en las sociedades receptoras, además de unas prácticas de intervención de atención y provi- 
sión de servicios destinadas hacia la población inmigrada (Montenegro, Galaz, Montenegro y Yufra, 2011). Esta matriz por la que se mueven las mujeres inmigradas tiene efectos de dominación en sus procesos de instalación social, considerando actuaciones y discursos de control, disciplina y normalización de sus actuaciones (Foucault, 1975).

Centraremos nuestra atención en uno de los nodos de esta matriz: la intervención social. En sus actuaciones se entrecruzan ejes múltiples como el origen nacional, el género y la clase, contribuyendo a la consolidación de diferencias irreductibles a nivel social, la construcción de subjetividades y los procesos de discriminación como también los de resistencia en contextos con alta presencia de mujeres inmigradas.

Si seguimos una perspectiva de género interseccional (Crenshaw, 1989; Collins, 2000) nos podremos fijar en el impacto de aquellas intervenciones sociales que están diseñadas para ciertos colectivos en el Estado español, "los sujetos inmigrados" considerados como minorías, construidos sobre la base de una desigualdad exclusivista, ya sea el género, la sexualidad, la clase, la procedencia, u otras. Por ello, cada vez se hace más evidente un análisis de las formas de diferenciación expresadas por este cruce de factores, que no sólo busque cuantificar a la población femenina que migra, dando volúmenes estadísticos o explicaciones globales de las causas de sus procesos migratorios, sino que también brinde luces sobre las relaciones de poder en las que emergen y se practican los mecanismos de categorización social que se desarrollan en las sociedades de instalación; y a partir de este proceso de diferenciación que se condensa en los sistemas de intervención social, visualizar de qué manera se refuerzan procesos de subalternización de este sector social respecto del grupo mayoritario (Dube, 2001). Así, en este artículo se busca analizar la generación de prácticas y discursos dentro de la intervención social, que se interconectan con prácticas políticas más generales, legales (ley de extranjería) y también económicas. A través de algunas ejemplificaciones nos centra- 
remos en la comprensión de las maneras en las que la relación entre personas interventoras y usuarias contribuye a estos procesos de diferenciación y de categorización social antes señalado.

\section{Visión cualitativa sobre las intervenciones}

Nos basamos en un meta-análisis de tres investigaciones postdoctorales llevadas a cabo en España. Estos estudios buscaron conocer y analizar los marcos de comprensión de la intervención mediante los cuales se trabaja actualmente con mujeres inmigradas en los servicios sociales de atención en ese país (públicos y de la Sociedad Civil). Creemos que este análisis puede dar luces para el contexto nacional chileno actual, sobre todo, ante el creciente interés gubernamental en poner como centro de atención a las personas inmigradas, y considerando las nuevas políticas sociales en ciernes (MIDESO, 2015). América Latina no es ajena a la creciente tendencia migratoria, principalmente en relación con flujos intrarregionales. Chile no ha estado al margen de esta situación. De hecho, a partir de los años noventa en adelante, el país -debido a su mayor estabilidad, desarrollo económico e ingresos per cápita comparativamente más altos que los países vecinos- ha comenzado a constituirse en destino de diversos grupos o colectivos migrantes provenientes en su mayoría de los países de la región latinoamericana. Por otro lado, la migración en Chile ha dejado de ser un fenómeno vinculado preferentemente a hombres jóvenes, pasando las mujeres a ocupar un lugar predominante en la configuración de los nuevos procesos migratorios, motivadas por la búsqueda de mejores condiciones de vida, oportunidades laborales y recursos económicos. Existe un predominio de mujeres, alcanzando el $60 \%{ }^{3}$. De ahí que resulte interesante analizar cómo

\footnotetext{
En los últimos 30 años, Chile en particular se ha vuelto un horizonte de instalación, que se ha acentuado a partir de los noventa (Tijoux, 2011), para diversos países latinoamericanos y de Centroamérica (Perú, Argentina, Bolivia, Haití, Colombia y Ecuador). El país, según algunos estudios, dispondría de 354.851 mil personas migradas lo que correspondería a un aproximado de un $2 \%$ de la población (Encuesta Casen, 2013). Sin embargo, el país tiene un gran desafío, sintetizado en lo que señalan Agar Corbinos y Pefaur Dendal (2013): "Chile desde su constitución como
} 
se ha actuado respecto de este colectivo a nivel de las intervenciones sociales.

Las investigaciones consideradas para este artículo se erigen desde un enfoque crítico de las ciencias sociales, específicamente desde las epistemologías feministas a través del concepto de "conocimiento situado" (Haraway, 1991/1995) y un análisis cualitativo de los datos recogidos. Esta postura epistemológica asume que la construcción de conocimiento es una práctica social que está involucrada en las relaciones de poder en las que se inserta dicha enunciación. Particularmente se concretó una exploración de 35 servicios dirigidos a mujeres inmigradas en tres de las capitales de las comunidades autónomas de España con más población migrada (Madrid, Barcelona, Valencia) a través de una triangulación de técnicas de recolección de datos: observación participante, entrevistas semiestructuradas y producciones narrativas, realizadas tanto a profesionales como a mujeres usuarias de dichos espacios (análisis de 50 elementos discursivos). La selección de los casos considerados se realizó a partir de un muestreo teóricamente conducido (Valles, 1999), es decir que se seleccionaron los sujetos participantes a través de criterios previamente establecidos que buscaron evidenciar la diversidad y variabilidad en los tipos de servicios de intervención social disponibles y experiencias migratorias de las mujeres inmigradas e interventoras.

\section{Procesos de diferenciación: categorías e intersecciones}

Como señalamos, la llegada de las mujeres inmigradas a España está influenciada por una matriz semiótico-material y relaciones de saber-poder (Foucault, 1975) que además están interconectadas con las relaciones de género predominantes y las formas de

Estado - Nación ha sobrevalorado la homogeneidad, la tranquilidad y la estabilidad por sobre otros derechos fundamentales. Es en este contexto en donde se generan discursos que desvalorizan la diversidad cultural, lo que produce una resistencia y un prejuicio bidireccional y contrapuesto, en donde la sociedad local discrimina a las comunidades inmigrantes" (2013: 4). 
organización social-económica que poseen las sociedades receptoras de inmigración en Europa. Cabe señalar que Europa desde hace más de 15 años se ha vuelto un horizonte de residencia para muchas personas inmigradas: primero de países ex colonias europeas (en España, en la década de los 90 se intensificó la llegada de población sudamericana), y posteriormente, fruto de las crisis económicas y políticas de regiones cercanas (africanas, asiáticas y medio oriente), (Galaz, 2009). ${ }^{4}$

La Unión Europea surgió con el objetivo de formar un mercado común europeo donde fuera posible la libre circulación de mercancías y también de personas. Dicho proceso ha favorecido las migraciones al interior de los Estados miembros, mientras que ha cerrado sus fronteras hacia las migraciones que no forman parte de dicha Unión, las llamadas migraciones "extracomunitarias" o de "terceros países". Esto ha hecho que no pocos estudiosos hablen de la "fortaleza Europa" (Stolke, 1994; Mezzadra, 2007; Geddes, 2008). Las migraciones que se dirigen a la Unión Europea forman parte de las denominadas migraciones Sur-Norte, encontrándose con fuertes marcos reguladores que pretenden limitar y controlar este tipo de flujos. Por ello, se ha intentado establecer una política común europea de inmigración para proporcionar un marco flexible de los países de la Unión Europea (UE) y se aplica de forma conjunta por los países y las instituciones de la UE. La política común se basa en algunos principios que orientan las leyes, normas y reglamentos. Su

$4 \quad$ Si bien la población residente en España disminuyó en 72.335 personas durante 2014 y se situó en 46.439.864 habitantes a 1 de enero de 2015, lo que demuestra un descenso en las cifras producto de la inestabilidad económica que vive el país, al momento en que se realizaron las investigaciones que sustentan este artículo, los índices de entrada se mostraban en constante alza. (Informe Instituto Nacional de Estadísticas español a junio de 2015. http://www.ine.es/prensa/np917.pdf consulta realizada en septiembre de 2015). En el último año, según lo muestran las cifras de la Agencia Europea de Control de Fronteras Externas, se han verificado entradas importantes de personas inmigradas -reflejadas constantemente por los medios de comunicación-, muchas de ellas en calidad de "refugio". Muchas de estas personas provienen de Oriente Medio (crisis en Libia), la presión demográfica en África y la emigración procedente de los Balcanes. Sin embargo, todavía esta situación no parece incidir considerablemente en las cifras españolas de residencia extranjera. (Consulta Frontex, septiembre de 2015, http://frontex.europa.eu/assets/Publications/Risk_Analysis/WB_Q2_2015_report. pdf) 
finalidad es asegurar que la inmigración sea en términos "regulares" y que contribuya preferentemente al desarrollo socioeconómico de la UE. Ante ello, se generan unos planes de integración en cada país, que luego bajan en determinados sistemas de intervención social que afectan la inclusión de las personas inmigradas en los respectivos territorios (Galaz y Montenegro, 2015).

Estos sistemas de intervención social suelen estar orientados desde políticas públicas, pero intermediados por una serie de entidades de la sociedad civil que son las articuladoras en la inserción social de las personas inmigradas. Al ser la prioridad el desarrollo económico de la Comunidad Europea, el énfasis en estos programas es la inserción socio-laboral de los nuevos sujetos residentes. Por ello, las principales acciones de inclusión generadas a nivel de intervención, como veremos más adelante, se relacionan con este ámbito, y con otros que logren posicionar a los sujetos en buenas condiciones para el mercado laboral: inmersión sociolingüística y social (Galaz y Montenegro, 2015).

Destacaremos que en los sistemas de intervención social hacia la población inmigrada y las mujeres en particular en España, se evidencian un conjunto de prácticas y operaciones de gobierno que permiten constituir, definir y organizar a estas poblaciones, de tal modo que no sea necesario que se tenga que recurrir, como señala Foucault, al ejercicio propio de la fuerza y la coerción del paradigma jurídico para poder ejercer poder (Foucault, 1975). De esta manera, los mecanismos de gubernamentalidad aplicados a este campo de estudio, implican una multitud de programas y políticas de intervención que buscan moldear la conducta de los individuos inmigrados a través del control, la disciplina y la normalización, como también todas aquellas propuestas que los hacen más inteligentes, contentos, emprendedores, “empowered", etc. (Rose, 1996). La intervención social como disciplina, se va erigiendo como uno de los nodos de esta matriz de poder, desde el que emergen las actuaciones directas en torno a fenómenos, colectivos o territorios señalados como problemas sociales y sobre los que se busca promover algún cambio social. 
Dicha transformación de los sujetos para su correcta adaptación al nuevo contexto, pasa por el establecimiento de una diferenciación que opera respecto de las mujeres inmigradas, donde se intersectan diversos factores que muchas veces son invisibilizados, en aras de la primacía de uno de ellos: género, clase, procedencia nacional/cultural. Nos situamos alejadas de una visión de la diferencia como una construcción políticamente neutra que señala las diferencias entre grupos de manera aséptica y esencialista, para utilizarla como diferencia jerarquizada, es decir, un problema relacionado con la posicionalidad y la asimetría (Anthias, 2002; Brah, 1992). Estas posiciones se relacionan con la intersección de factores que hace que en un contexto y momento histórico, una característica social prime por sobre otras. Así, aquello que constituye una diferencia significativa o marca de opresión en un contexto determinado, no es un atributo fijo y estable, sino una relación contingente y situada que se moviliza en cada práctica.

El establecimiento de las diferencias es así relacional y contextual que, a su vez, se articula con otras diferencias específicas. Es decir, una diferencia significativa o marca de opresión como la de inmigrante, es una relación contingente y situada que se moviliza en cada práctica, esto es, atendiendo siempre a sus contextos de emergencia (Crenshaw, 1989). Es decir, la situación de migrante, la de mujer, la de trabajadora, se vuelve significativa para las interventoras entrevistadas en el contexto español, y esa articulación es vista como problema a tal punto, que genera la justificación para desarrollar dispositivos de intervención apropiados de encuadre de conductas que se consideran fuera de la norma -mientras que para otros contextos espaciales o temporales, pudieran no llegar a ser ni siquiera una categoría de enunciación a nivel problemático.

Siguiendo la crítica que elabora Yuval-Davis (2006) a la idea de doble o triple discriminación por ejes de diferencia, entendemos que si bien las desigualdades tienen bases ontológicas propias, a la vez, están interrelacionadas y lo hacen estando en un contexto y momento histórico determinado: es decir que las intersecciones pueden dar como resultado desigualdades complejas pero siem- 
pre situadas en un contexto, en este caso el español-europeo. En ese sentido, no se trata de aplicar una lógica aditiva de desigualdades (mujer-inmigrante-trabajadora, por ejemplo), sino más bien comprender que estos cruces de ejes de diferencia provocan una situación específica de desigualdad y de poder que requiere de soluciones ad hoc. De ahí la necesidad de no mirarlas sólo desde una perspectiva intersubjetiva sino también cómo operan en los niveles institucionales-organizativos de la sociedad y en el representativo-discursivo, como es el caso de las intervenciones sociales por las que cruzan las mujeres inmigradas.

\section{De la categorización a actuaciones que apoyan la subalternización}

La actuación de los servicios sociales que se ofrecen a mujeres inmigradas ${ }^{5}$ en la sociedad de recepción española, contribuye a la consolidación de categorías estigmatizadoras respecto de ellas que se activan de diversa forma cuando se busca encauzarlas para incluirlas socialmente. Por ejemplo, en los discursos analizados, pudimos ver cómo emergen discursos dicotómicos excluyentes que validan las acciones de intervención: mujer-hombre, autóctona-inmigrante, interventora-intervenida, desarrolladano desarrollada, etc. A partir de estas distinciones se articulan acciones para poder integrarlas al conjunto social ya sea como inmigrante, como sujeto que está en una situación menor de desarrollo que la sociedad de acogida, como mujer vulnerable, entre otras nominaciones.

Es importante hacer notar que la tendencia de inmigración en España ha ido cambiando en los últimos años: si bien hasta hace unos tres años, primaba la llegada de personas marroquíes, ecuatorianas, dominicanas, argentinas, asiáticas (Paquistán, India, China), entre otras (Galaz, 2009), en el último año según el INE español, las principales nacionalidades de los inmigrantes extranjeros fueron la rumana (con 29.968 llegadas a España durante 2014), la marroquí (con 20.163) y la italiana (con 14.955). La población inmigrada sigue una tendencia de feminización (un $48 \%$ de mujeres en España). (INE español, 2015, consulta realizada en septiembre de 2015, http://www.ine.es/prensa/np917.pdf) 
Las intervenciones a través de la activación de este imaginario simbólico sobre las mujeres inmigradas, tienen una "eficacia social" (Maffessoli, 2003), logrando efectos en su ubicación social y en los procesos de subjetivación ya que reproducen mayormente las relaciones de poder hegemónicas: las personas migradas surgen como minorías, sujetos en falta, vulnerables por excelencia, que deben ser respaldadas para que se introduzcan a la normalidad social, para que alcancen el estándar de la mayoría -que sería el supuesto modus vivendi de la población autóctona. Como plantea Romero:

"Los efectos disciplinadores y normativizadores que se movilizan con el "reconocimiento" -que se construye sobre una cierta ficción- de las "mujeres inmigrantes" trabajan sistemáticamente en la incorporación de los "cuerpos-sujetos" así interpelados a los espacios delimitados como propios de "mujeres inmigrantes". Un espacio caracterizado por la vulnerabilidad, la discriminación y la denegación de los derechos vinculados a la posición de ciudadanía." (Romero Bachiller, 2007, p. 187).

Ahora bien, diremos que las categorizaciones que vemos operando en los dispositivos de intervención social funcionan como marcadores de diferencia que posibilitan su integración en una situación de subordinación. Así, la categorización de inmigrante y de Mujer del Tercer Mundo se solidifica en las actuaciones, aportando a un proceso social, político, económico y de transacciones simbólicas que le ubica en los márgenes del sistema, en una situación de subalternización social (Galaz, 2009).

Este distanciamiento y jerarquización social entre mayoría/minoría puede observarse en los estudios realizados claramente en el tipo de dedicación laboral que es favorecida para los grupos migrados, específicamente las mujeres inmigradas, sobre todo en actividades periféricas como: trabajo sumergido, labores de cuidado y acciones de proximidad, además caracterizadas por condiciones sociales precarias. Las mujeres inmigradas son legitimadas en un espacio único, dada su condición de género y dada su posición de extranjeridad culturalizada: como son vistas en sus roles de reproductoras 
de los roles de género, las labores de cuidado (niños/as, adultos mayores, servicios domésticos), son los espacios exclusivos donde podrían desenvolverse con mayor fluidez y para lo cual son formadas y estimuladas desde las intervenciones sociales. Por tanto, con las intervenciones se mantiene el statu quo en las relaciones hegemónicas de género en conjunción con la subordinación económica, al ubicar a las mujeres inmigradas en el espacio de cuidado que dejan las autóctonas para que estas últimas puedan participar económicamente. Las relaciones de poder por razones de género y clase, actúan al unísono como algo esencial e incuestionable.

Siendo así, la configuración de mujer inmigrante está atravesada por criterios culturales y de procedencia pero también de clase: se sitúa a posteriori de la categoría de extranjero/a comunitario/a (mujeres que vienen de otros países de Europa) o de un estatus económico alto (estudiantes residentes). De las mujeres inmigradas se tiende a hacer una generalización más allá de su país de origen y se tiene un imaginario de clase, ubicándolas como sujetos subalternos dentro del sistema, en condiciones de precariedad y como competidoras con cierto sector local.

Dentro de esa categorización, a diferencia de lo que pueda pensarse, las mujeres inmigradas no emergen como sujetos invisibles, sino que se encuentran en una situación de excesiva visibilidad a partir de esas diferencias: nacionalidad, género y clase. En esta articulación surgen formas de inclusión social, pero como sujetos subordinados y por tanto, con menos posibilidad de ejercicio de derechos. En otras palabras, las mujeres inmigradas están dentro pero bajo una lógica de "inclusión perversa" (Sawaia, 2002); incluidas pero en los bordes del sistema, donde gran parte de la población no desea habitar.

\section{Adaptación cultural y trabajo: ejes primordiales de inclusión}

En lo que sigue se presentan algunos ejemplos en los que se busca condensar algunas de estas dinámicas de diferenciación y subalternización en las intervenciones sociales analizadas. De acuerdo 
al trabajo de campo se pudo visualizar que los dispositivos de intervención por los que cruzan las mujeres inmigradas se plantean en su gran mayoría como espacios de intermediación entre la inserción efectiva social y las necesidades que manifiestan las usuarias. En ese sentido, comienzan a asumir una función no explícita en sus misiones institucionales: dar respuesta al llamado a la integración a la que son exhortados desde las políticas de integración a nivel nacional y a nivel europeo, que en su mayoría tienen a su vez, un carácter claramente asimilacionista.

Por ello, la mayoría de las entidades plantean sus objetivos con el fin de desarrollar espacios de formación, preparación y asesoría para la inclusión de los contingentes inmigrados. Gran parte de los servicios analizados, tanto públicos como privados, responden a este llamado en dos sentidos: uno, poniendo un énfasis casi exclusivo en la dimensión cultural; y por otro, en la integración economicista a partir de la inserción laboral.

Para ello, la mayoría de las acciones desarrolladas en los servicios analizados consideran áreas que suman a estas dos grandes metas: cursos de idiomas (en pos de una mejor inserción laboral), formación socio-laboral y de apresto laboral, formación sobre el entorno -adecuación cultural a la lógica mayoritaria; normativas para regularización legal- principalmente sobre las visas laborales; sensibilización de empresas y sensibilización social -donde la mayoría de las acciones tienen que ver con la promoción de diversos hechos culturales distintivos por nacionalidad-. De esta manera, se visualiza una cierta folklorización de las diferentes características culturales de los países, la que queda expresada cuando se destaca la promoción de algunas actividades concretas (muestras gastronómicas, conciertos musicales, etc.), actividades promovidas desde los dispositivos de intervención. Éstas son maneras en las que se fija y generaliza cierta forma cultural -folklórica- como característica general de un grupo concreto. En la siguiente cita podemos ver este afán:

"Hemos hecho diferentes actividades donde ellas han participado con sus cosas, sus costumbres gastronómicas, sus bailes, y eso nos 
ha servido para acercarnos, para integrarlas". (Entrevista 4. Interventora $\mathrm{ONG})$.

Gran parte de las mujeres inmigradas del estudio plantean a su vez que el acceso al trabajo es parte sustantiva de su inclusión social al nuevo entorno. En función de su ingreso laboral se mide el éxito del proyecto migratorio y el posicionamiento que obtienen en su comunidad de origen. De ahí que el trabajo no sólo sea medido como fuente de ingreso, sino también como parte fundamental para la subjetivación de las mismas mujeres inmigradas.

Por ello, es importante tener en cuenta el acceso a trabajos secundarios que son promovidos desde las intervenciones sociales para estas mujeres, ya que gran parte de estas labores están estigmatizadas negativamente por la comunidad de instalación y muchas de ellas son abandonadas por las clases sociales del país ya sea por su baja cualificación, las condiciones de precariedad en que se sostienen, la baja remuneración, entre otros factores. Este fenómeno no hace más que profundizar la estigmatización de las mujeres inmigradas y no considera que este proceso de inserción se genera bajo las condiciones y oportunidades limitadas que brinda la sociedad de instalación.

Los dispositivos, si bien responden a las urgentes necesidades que portan las mujeres inmigradas, a la vez ajustan su accionar a las formas de funcionamiento neoliberal para promoverlas en espacios específicos laborales y educativos marginales, especialmente de mano de obra barata. Como señalamos, existe una tendencia a la promoción de éstas en ámbitos de cuidado, de servicios domésticos, de servicios de hostelería y de limpieza industrial. Muchas veces esta adaptación se da bajo otras limitaciones sociales:

- Las mujeres están impedidas de regularización de sus visados debido a la complejidad que comporta la ley de Extranjería de España.

- Por los prejuicios sociales generalizados sobre algunas nacionalidades -marroquíes, paquistaníes, indias principalmente-; 
lo que les dificulta la inserción de manera más rápida e independiente de apoyo.

- Prejuicios económicos -se les considera que por su condición de extranjeras son adaptables a las condiciones de los/las empleadores/as en cuanto a sueldo y horario.

- Prejuicios de los mismos servicios -se homogeneiza al conjunto de mujeres bajo la etiqueta vulnerable.

- Presiones de género, ya que el mercado llama preferentemente a mujeres para las labores que antes ejecutaban de manera gratuita otras mujeres del país.

En estas formas de respuesta de los servicios, se parte de una lógica de tabla rasa y se invisibiliza la historia previa de las mujeres, tanto de agencia personal como en cuanto a sus niveles educativos. Incluso se pudo visualizar que en el caso de muchas mujeres inmigradas que recurren a estos servicios, se da cierto "desclasamiento social". Es decir, que en el afán de encontrar trabajo de forma rápida, las mujeres aceptan condiciones y posibilidades laborales, en situaciones más precarias que el estatus socioeconómico esperado y que mantenían en sus países de origen, con la esperanza de que en el futuro esto pueda ajustarse. Esta situación afecta principalmente a mujeres con estudios intermedios, profesionales y universitarias, quienes trabajan sin contrato, o en empleos con baja protección social.

De esta manera, el camino de las mujeres que recurren a estos servicios tiene esta marca de género, culturalista y de clase: pasar por procesos de formación para la integración laboral que muchas veces no se relacionan con su nivel de estudios y que se relacionan con su condición de ser mujeres, exhortos constantes para su adecuación al mercado, y finalmente, la adaptación y moderación de sus costumbres culturales en aras de una supuesta mejor integración.

Se tiende, así, a una cierta asimilación encubierta ya que el discurso privilegia la idea de que la manifestación de hechos culturales 
puede entorpecer la incorporación efectiva o generar discriminaciones del resto de la sociedad por la falta de comprensión. Así se responde al llamado a la integración que viene de las políticas sociales más macro, y por tanto, los dispositivos de intervención social se constituyen como espacios de control y disciplina de los cuerpos femeninos, en el sentido de que sus acciones y discursos se dirigen principalmente a "re-educar" a esas "otras culturales" para su correcta inclusión social. En las investigaciones se pudo ver cómo se les aconseja esta adaptación, por ejemplo, en:

- los usos de vestimentas y colores para que se acerquen a la norma europea y estandarizada,

- a quienes usan velo islámico, recomendaciones de moderar su uso o su eliminación,

- usos de maquillaje neutros,

- formas de expresión verbal y tonos de voz neutros,

- simulaciones de entrevistas laborales que corrigen su ubicación espacial y comportamientos,

- difusión de normas sociales españolas en el uso del espacio público.

A veces desde los servicios analizados se argumenta que es necesario cambiar ciertas costumbres de las mujeres inmigradas para que no constituyan precisamente un obstáculo para la inserción efectiva de ellas mismas, incluso como una manera de evitar actitudes racistas, por ejemplo, a la hora de buscar trabajo. Esta postura asimilacionista surge sobre todo por razones religiosas y culturales ya que en el contexto español existe una serie de estereotipos respecto a supuestas exigencias religiosas musulmanas, vistas como una contención de la libre expresión de las mujeres (sobre todo, referido al uso del velo). Esto se hace situando como parámetro de comparación a la mujer-europea-occidental, dando por cerrada cualquier discusión sobre ésta, como si en el contexto español los debates de diferencia de género estuviesen superados. Así lo vemos en estas citas: 
"Es que en el fondo para conocer una cultura hay que rozarse mucho con esa cultura. Hemos de procurar ayudarlas para que cuanto antes sean autónomas y sólo entonces nos daremos cuenta si estamos en igualdad de condiciones para entablar diálogo, y si realmente ellas quieren convivir realmente e incluirse". Entrevista profesional. 19 Servicio Público.

"Con la gente sudamericana son mejores que con nosotras porque dicen que se parecen más, y también con los chinas, porque son más calladas, pero a nosotras porque como somos musulmanas, entonces, inmediatamente te rechazan y te piden que te saques el velo si quieres encontrar trabajo". Entrevista usuaria marroquí 23.

En resumen, la configuración que se hace de sujeto, basada en la diferencia cultural, en el género y la clase, hace que se asuma como necesaria la asimilación para una verdadera inclusión. Por tanto, las intervenciones derivan en actuaciones que plantean la necesidad de una cierta uniformización cultural, lo que implica que los grupos minoritarios acepten priorizar la lengua, valores, normas y aspectos simbólicos de la cultura dominante. Tal como se ve ejemplificado en esta cita:

"A la gente les duele mucho que las inmigrantes hagan muy poco por integrarse. Si ellas dieran pasos por integrarse, la gente los acogería mejor. A la gente que da pasos les acogen mejor y en eso les ayudamos desde aquí". Entrevista profesional 16. Servicio Público.

\section{Acento culturalista y binomio Ellas/Nosotras}

Por otra parte, el acento culturalista de las intervenciones también queda reflejado en que se persiste en trabajar con esta población como si fuera un conjunto homogéneo y compacto desde un punto de vista cultural. Se consolida así una relación basada en el binomio Ellas/Nosotras. El Nosotras tiene características culturalistas, marcadas por un acento de prioridad nacional-española. Creemos que esta visión de una realidad homogénea en torno a la procedencia se puede apreciar en un discurso que privilegia casi exclusivamente al endogrupo como espacio de relación y norma. Esta preferencia 
vendría dada por la idea de nacionalidad, categoría que marca bastante las formas de posicionarse unas personas respecto de otras.

La pertenencia grupal se observa en aseveraciones tales como el "ser española" y "ser de otros países", la contraposición entre "extranjeras y nacionales", entre "ellas" y "nosotras", entre las que "somos de afuera" y las que "son de aquí, entre otras nominaciones. Muchas veces se reiteran aseveraciones como "nosotros no somos asi'”, "a nosotros nos gustan las cosas diferentes", "éstas son así", "es típico en este grupo", "lo llevan en su cultura", o, "ese tipo de mujeres". Esta forma de catalogación, refleja una cierta esencialización de las personas de acuerdo a su nacionalidad y referente cultural. Nacer en un contexto terminaría siendo asociado a ciertos criterios culturales inamovibles que, al parecer, les marcarían de por vida.

Se evidencia que en esta construcción diferencial de las interventoras respecto de las otras, se producen y reproducen una serie de representaciones sociales, a veces restrictivas, que simplifican las realidades de las mujeres inmigradas principalmente a partir de la generalización de prejuicios, estereotipos y estigmatizaciones socioculturales.

Esta separación entre Ellas y Nosotras, a nuestro entender, reforzaría unas ciertas relaciones jerarquizadas que se refuerzan en discursos tales como: "primero debemos considerar las necesidades de las nacionales", "tendrían que tener prioridad las españolas y luego cuando se vea que las de acá están bien, que se dé a ellas", o, "las de aquí lo hemos superado y ellas no". Este discurso de diferenciación de Ellas/Nosotras estaría influido también por la posición de poder en que se sitúa la comunidad de recepción, como grupo mayoritario, dentro del entorno social, como lo vemos en el siguiente ejemplo:

"Un aspecto negativo es el hecho de que sean de una cultura diferente... además son mujeres subyugadas muchas veces por esa cultura... y esto provoca que no se puedan relacionar y allí es donde tenemos que intervenir". Entrevista profesional 7. ONG. 
Se podría sostener que esta extrañeza cultural, si bien se basa en una extranjería política (porque se trata de personas no nacionales) también da el sustento para una cierta extranjería social (Santamaría, 2002), al considerar a esas personas como foráneas en los aspectos socioculturales habituales. Esta cierta extranjería social es la que justifica que desde las intervenciones sociales se catalogue a las personas inmigradas bajo estereotipos o, incluso, estigmatizaciones a partir de ciertos rasgos culturales considerados ajenos a lo aceptado. La extranjería social queda graficada en diferentes catalogaciones que se hacen sobre las mujeres inmigradas elaboradas desde una perspectiva asimétrica, ya que las interventoras se posicionan como el grupo mayoritario dentro del contexto local. Por tanto, también se inscriben en dinámicas de saberpoder (Foucault, 1975).

Persiste la idea en muchos dispositivos de atención que algunas características culturales estarían en un estatus menor respecto de las del grupo de referencia local. Aparece, así, la asociación de la mujer inmigrante con ideas generales basadas en una supuesta deficiencia de los grupos a los que pertenecen, que se justificaría en las razones económicas para su emigración (discurso paternalista y utilitarista de la inmigración); o en una diferenciación de lo que se considera como civilizado y desarrollado y, por tanto, de lo no civilizado y atrasado; así como también por cierta peligrosidad social que, supuestamente, la inmigración puede significar para el contexto local (al asociar, por ejemplo, delincuencia a inmigración; la pérdida de calidad del entorno con la llegada de personas extranjeras, o la pérdida de valores culturales por la supuesta radicalidad de ciertos grupos sociales, etc.).

Parte de las interventoras destacan que el sistema social -español, europeo y occidental- poseería rasgos más positivos que los de otros países. Se denota una cierta jerarquización social. Ello conllevaría aprensión a las influencias de otros sistemas socioculturales que puedan provocar la pérdida de lo considerado como propio, homogéneo y supuestamente más valioso. Como hemos señalado anteriormente, en estos recelos subyace también la apre- 
ciación de que las personas son fieles reflejos de sus contextos de origen, y son vistas como un todo homogéneo. De esta manera, se justifican las intervenciones hacia las mujeres inmigradas, poniéndolas como el ícono del problema social general que es la "inmigración". En este proceso no se gira la mirada hacia las condiciones que la sociedad de instalación entrega hacia esas personas y las tramas de poder en las que se insertan. Entonces, se consolida el imaginario de las mujeres extranjeras casi exclusivamente como portadoras de cultura, como mujeres y como trabajadoras, es decir, su estatus de género y condición socioeconómica y entendida como representante de toda una cultura. Con ello, no sólo se crea la idea de una cultura homogénea, sino a la vez nos imposibilita cuestionar determinadas desigualdades de género ya que al cuestionarlas, estaríamos cuestionando a todo ese marco cultural (Burman, 2005).

Esta categorización Ellas/nosotras termina por ofrecer un lugar neocolonial en las relaciones entre sujetos interventores y mujeres intervenidas: la construcción generalizada de la "Mujer del Tercer Mundo" (Mohanty, 2003). Es esa construcción paternalista particular de las mujeres de diversos orígenes, y la implícita auto-representación de la mujer blanca y experta que la interviene, la que justifica prácticas humanistas y occidentales que se basan en la idea de otra diferente. Así implícitamente la misión de las interventoras es civilizar a esas otras culturales, que emergen como débiles y carentes en los conocimientos y habilidades que se requieren para habilitarse en su nuevo espacio de habitación.

Por tanto, como dijimos, se evidencia un cierto discurso de superioridad por parte de quienes se ubican como interventoras. Surge la idea de que la situación socioeconómica y cultural y las luchas de género de la comunidad local estarían más avanzadas y, por tanto, las personas inmigradas poseerían concepciones, incluso formas arcaicas de pensar, de sentir o de relacionarse (civilizadas/ no civilizadas). Por ejemplo, algunos casos puntuales en algunas intervenciones sociales asumen que las mujeres inmigradas carecen incluso de las habilidades cognitivas suficientes para poder 
desarrollar un correcto aprendizaje para su inserción en el nuevo contexto, debido a la supuesta falta de competencias anteriores del marco cultural del que procedían. Ante ello, se les debe enseñar para que su inserción en el nuevo espacio sea efectiva.

Algunos discursos de mujeres interventoras se refieren a los países de procedencia de las mujeres inmigradas como "escasamente desarrollados", "con malas condiciones sociales", "sumidos totalmente en la pobreza", "con poca libertad", "con desintegración social”, o, “con escasa educación”. Estas concepciones no hacen más que reforzar actuaciones paternalistas respecto de las mujeres inmigradas que transitan por esos servicios. Esto se refleja en los siguientes ejemplos:

"Estos barrios se han degenerado mucho, se ve mucha basura, la situación económica que tienen estas personas hace que vivan de una manera, cosas que se ven sobre las mujeres que aquí son impensables... Pero también hay que re-educar, a mostrar cómo se hacen las cosas aquí, es que a veces también no tienen la preparación para comprender todo porque algunas personas no han estudiado nunca, y entonces hay que empezar de cero". Entrevista Profesional 20. Servicio público.

"Se les dice que no hay trabajo para todas pero que hay que enseñarles a trabajar, como si allá no se supiera trabajar". Entrevista Profesional 22. ONG.

En ese sentido, creemos que este afán civilizatorio de las interventoras al usar la categoría de la "Mujer del Tercer Mundo" continúa reforzando la desigualdad de género a través de la diferenciación cultural y de la inclusión en espacios mal considerados por la mayoría.

\section{Conclusiones}

Todo el imaginario simbólico que opera desde las intervenciones sociales sobre las mujeres inmigradas tiene una manifestación concreta en las formas de relación cotidiana que se dan en éstos y que está basado en relaciones de saber-poder (Foucault, 1975). En 
esas relaciones, las personas interventoras aparecen como las expertas que deben guiar el camino de estas mujeres para que puedan encontrar puerto seguro a nivel de inclusión social. Gran parte de estas actuaciones son respuestas implícitas o no directas al llamado a la integración que realizan las políticas generales europeas de control de la inmigración.

Esta construcción social de las mujeres inmigrantes en una situación de infravaloración, como mujeres en falta, termina afectando también las condiciones efectivas de inclusión al nuevo contexto. En cierta manera, la eficacia social de lo imaginario (Maffesoli, 2003) permite la construcción de un escenario con menos posibilidades para que estas personas sean consideradas como "ciudadanas" legítimas en igualdad de condiciones. "El vínculo se configura alrededor de imágenes que compartimos con los demás. Puede tratarse de una imagen real o de una imagen inmaterial, o incluso de una con la que comulgamos, cualquiera que sea. Lo que por el contrario me interesa aquí es que esta 'cosa mental' tiene una eficacia que no se puede ignorar" (Mafessoli, 2003, 152).

El énfasis culturalista en las intervenciones da pie a considerar a los grupos sociales como entidades compactas, dejando al margen la variación sociocultural social y la libre determinación personal de las mujeres. A partir de esta concepción identitaria culturali$z a d a$, traspasada además por la clase y el género, se consolida una distancia entre un Nosotras y un Ellas que legitima la ubicación de estas últimas en espacios de subordinación social.

Así, la diferencia jerarquizada es el vector central que se da en la relación de intervención. Desde esta perspectiva jerarquizada aparece una cierta alteridad lejana, la que es asignada a las mujeres inmigradas con características culturales puntuales (especialmente las catalogadas como no occidentales) y en cierta posición económica de desventaja. En esta escala, emerge en un extremo negativo la figura de la alteridad máxima: la mujer musulmana, ícono por excelencia de la necesidad de control, disciplina y normalización. 
El uso de todos estos discursos negativos genera que: a) se desdibuja la posibilidad de transformación de carácter individual que tienen las mujeres - posibilidad de agencia-, b) se deje a un lado la heterogeneidad cultural que todo grupo social posee, y c) se censure la posibilidad de transformación y mestizaje en el nuevo contexto. En definitiva, las comunidades de mujeres inmigradas surgen, por un lado, etiquetadas bajo conceptualizaciones culturalistas y de género, considerándolas como extrañas y atrasadas; y por otro, como sujetos económicos que compiten por los mismos puestos laborales, aun cuando muchas se sitúan en espacios secundarios donde la comunidad de recepción va en retirada.

Esta diferencia jerarquizada redunda en un proceso de subordinación de los colectivos sociales considerados como vulnerables, al considerarlos una desviación de lo esperado por la sociedad española. Lo normal para las interventoras viene marcado por la aceptación de ciertos rasgos culturales y de ciertos nichos laborales, lo que trae como consecuencia el desarrollo de distintos dispositivos de control para evitar la desviación del grupo mayoritario. Así, el concepto de nacional es representado en directa oposición al concepto de inmigrante con todas las consideraciones sociales que ello significa (como la misma calidad de ciudadanía). No obstante, se aprecia en este proceso una invisibilidad de lo que significaría ser culturalmente nacional, dejando esta caracterización de diferenciación exclusivamente a las mujeres inmigradas. Esto redunda en que la integración corresponda sólo a las culturalmente diferentes y en una situación de desventaja socioeconómica.

Finalmente, como señala Bauman, toda esta configuración sobre los sujetos inmigrados, a la que contribuye la intervención social como dispositivo de integración social, genera efectos materiales y simbólicos de distanciamiento entre la comunidad nacional y las nuevas residentes:

"Se produce un apartheid à rebours: los que tienen medios suficientes abandonan los distritos sucios y sórdidos, a los que están 
atados aquellos que carecen de esos medios. El centro no existe en sus vidas. No se puede conversar por encima de la frontera. Sus experiencias vitales son radicalmente distintas" (Bauman, 1999, 114).

\section{Bibliografía}

Ahmed, S. (2000). Strange encounters. New York \& Londres: Routledge.

Amorós, C. y De Miguel, A. (Eds.) (2005). Teoría feminista. De la Ilustración a la globalización. Madrid: Minerva.

Agar Corbinos, L. Pefaur Dendal, D. (2013). Refugio en Chile: el proceso de intervención social en contexto de globalización y posmodernidad. En Avaria, A. Desafíos de la migración ¿Cómo acercarnos a las personas inmigrantes? Miradas de $y$ desde la investigación e intervención social. Santiago de Chile: Ediciones de la Universidad Santo Tomás: RIAL.

Anthias, F. (2002). Beyond feminism and multiculturalism: locating difference and the politics of location. Women's Studies International Forum, 25(3), 275-286.

Bauman, Z. (1999). La globalización. Consecuencias humanas. Buenos Aires: Editorial Fondo de Cultura Económica.

Brah, A. (1992). Diferencia, diversidad y diferenciación. En Bell Hooks, Avtar Brah, Chela Sandoval, Gloria Anzaldúa, Aurora Levins Morales, Kum-Kum Bhavnani, Margaret Coulson, M. Jacqui Alexander y Chandra Talpade Mohanty (Eds.), Otras inapropiables. Feminismos desde las fronteras (pp. 107-136). Madrid: Traficantes de Sueños.

Burman, E. (2005). Engendering Culture in Psychology. Theory and Psychology, 15(4), 527-548.

Butler, J. (1997/2004). Lenguaje, poder e identidad. Madrid: Síntesis.

Crenshaw, K. (1989). Demarginalizing the intersection of Race and Sex: A Black Feminist Critique of Antidiscrimination Doctrine, Feminist Theory and Antiracist Politics. Chicago: University of Chicago Legal Forum.

De Lauretis, T. (1984). Alicia Doesn't. Feminism, Semiotics, Cinema. Indiana University Press: Bloomington.

Dube, S. (2001). Sujetos Subalternos. México: El Colegio de México.

Foucault, M. (1975). Vigilar y castigar. Nacimiento de la prisión. Madrid: Siglo XXI Editores (6 ${ }^{a}$. ed. en España, 1988).

Foucault. M. (1975). Defender la sociedad. Argentina: FCE, 2008. 
Foucault, M. (1977). El juego de Michel Foucault. En: Saber y verdad (127-162). Madrid: Las Ediciones de la Piqueta, 1991.

Foucault, M. (1999). La gubernamentalidad, En Obras Esenciales, vol. III: estética, ética y herméutica (pp. 175-187). Barcelona: Paidós.

Galaz, C. (2009). Las relaciones de cooperación y exclusión entre personas con referentes socioculturales diversos. Un estudio sobre la alteridad. Universidad Autónoma de Barcelona.

Galaz, C. y Montenegro, M. (2015). Gubernamentalidad y relaciones de inclusión/exclusión: los dispositivos de intervención social dirigidos a mujeres inmigradas en España. Revista Universitas Psychologica. Aceptada para publicación.

Geddes, A. (2008) Immigration and European Integration: Beyond Fortress Europe? Manchester. Manchester University Press.

Gregorio, C. y Franzé, A. (1999). Intervención social con población inmigrante: esos “otros" culturales. Intervención Psicosocial, 8(2), 1-14.

Haraway, D. (1991/1995). Ciencia, cyborgs y mujeres. La reinvención de la naturaleza (pp. 313-345). Madrid: Ediciones Cátedra.

Juliano, D. (1998). Las que saben. Subcultura de mujeres. Madrid: Horas $\mathrm{y}$ horas.

Maffesoli, M. (2003). El Imaginario Social. No 198. Barcelona: Anthropos.

Mezzadra, S. (2007). Fronteras, migración y ciudadanía. Papers. Revista de Sociología, 85(0), 31-41. http://doi.org/10.5565/rev/papers. 2009

MIDESO (2015). Inmigrantes en Chile: Oferta programática, participación, inclusión y vulnerabilidad. Ministerio de Desarrollo Social- Trabajo Social Universidad de Chile. Santiago. Publicación pendiente.

Mohanty, C. (2003). Feminism without borders. Decolonizing theory, practicing solidarity. Durham y Londres: Duke University Press.

Montenegro, K. y Montenegro, M. (2013). Governmentality in Service Provision for Migrated Women in Spain. Social and Personality Psychology Compass, 7(6), 331-342.

Montenegro, K.; Montenegro, M.; Yufra, L. y Galaz, C. (2010). 'Juventud inmigrante': Procesos de diferenciación y categorización social en los servicios de inserción laboral. Revista de Estudios de la Juventud (INJUVE), 89, 143-161. 
Montenegro, M. y Balasch, M. (2011). Conceptes i teories sobre problemes socials. En M. Montenegro (coord.). Intervenció Social. Controvèrsies teòriques i metodològiques (25-67). Barcelona: editorial UOC.

Montenegro, M., Galaz, C., Yufra, L. y Montenegro, K. (2011). Dinámicas de subjetivación y diferenciación en servicios sociales para mujeres inmigradas en la ciudad de Barcelona. Athenea Digital, 11(2), 113-132.

Montenegro, M.; Montenegro, K.; Galaz, C. y Yufra, L. (2009). MDG’s in a global world. Gender equity and empowerment in service provision for migrant women in Barcelona. Journal of Health Management, 11(1): 49- 63.

Morales, L., Bhavnani, K., Coulson, M., Alexander, M. J. y Mohanty Ch. (2004). Otras inapropiables. Feminismos desde las fronteras. (pp. 9-32). Madrid: Traficantes de Sueños.

Nash, M. (2005). La doble alteridad en la comunidad imaginada de las mujeres inmigrantes. En Mary Nash, Rosa Tello y Núria Benach (Eds.), Inmigración, género y espacios urbanos. Los retos de la diversidad. (pp. 17-32). Barcelona: Edicions Bellaterra.

Romero Bachiller, C. y García-Dauder, S. (2003). Saturaciones identitarias: de excesos, materialidades, significación y sus (in)visibilidades. Clepsydra, 2, 37-56.

Romero Bachiller, C. (2007). El exotismo de los cuerpos y la fetichización de la mirada en la producción de las «mujeres inmigrantes» como «otras». En M. J. Sánchez Leyva y A. Reigada (coords.). Crítica Feminista y Comunicación (186-214). Sevilla: Comunicación Social.

Sassen, S. (2003). Contrageografías de la globalización. Género y ciudadanía en los circuitos transfronterizos. Madrid: Traficantes de sueños.

Solé, C. (2000). Inmigración interior e inmigración exterior. Papers, 60, 211- 224.

Spelman, E. (1988). Inessential Woman, Problems of Exclusion in Feminist Thought. Boston Masachussets: Beacon Press.

Stolcke, V. (1994) Europa: nuevas fronteras, nuevas retóricas de exclusión, en $A A . V V$., Extranjeros en el paraíso, Virus, Barcelona (pp. 235-266).

Tijoux, M.E. (2011) Trayectorias Laborales de los Inmigrantes Peruanos en Chile: Estrategias de Estructuración de la Movilidad Ocupacional Ascendente. Entidad: Universidad Alberto Hurtado. Función: Co-investigadora. Fuente de Financiamiento: Fondecyt Proyecto Fondecyt regular No 1100793. 
Dinámicas de diferenciación y desigualdades. El caso de las intervenciones sociales hacia mujeres inmigradas en España / Galaz

Valles, M. S. (1999). Técnicas Cualitativas de Investigación Social. Reflexión metodológica y práctica profesional. Madrid: Sintesis.

Yuval-Davis, N. (2006). Intersectionality and feminist politics. European Journal of Women's Studies, 13, 193-209. 